\title{
Ear Stick Dosage Form
}

National Cancer Institute

\section{Source}

National Cancer Institute. Ear Stick Dosage Form. NCI Thesaurus. Code C149462.

Solid single-dose preparation of usually conical shape intended to be inserted in the external auditory meatus where it melts or dissolves. 